\title{
"O anjo da história do Brasil”: a alegoria em abismo em Píer, de Sérgio Alcides
}

\section{Eduardo Horta Nassif Veras}

Universidade Estadual de Campinas, Campinas, Brasil

eduardohnveras@yahoo.fr

Resumo: Este artigo apresenta uma breve análise sobre o conceito benjamininano de alegoria e o emprego dessa figura na poesia de Sérgio Alcides. Pretende-se evidenciar, a partir do comentário sobre alguns poemas de Píer (2012), a relação que a alegoria estabelece com a concepção essencialmente crítica de poesia posta em prática pelo poeta carioca.

Palavras-chave: Alegoria. Walter Benjamin. Poesia brasileira contemporânea. Sérgio Alcides. Mise en abyme.

Abstract: This article presents a brief analysis of Walter Benjamin's concept of allegory and its use in Sérgio Alcides's oeuvre. The relationship between allegory and an essentially critical concept of poetry will be developed by the reading of some poems of Pier.

Key-words: Allegory. Walter Benjamin. Brazilian contemporary poetry. Sérgio Alcides. Mise en abyme.

[...] la Nature est un verbe, une allégorie, un moule, un répoussé, si vous voulez. (Charles Baudelaire, carta a Alphonse Toussenel, 21 de janeiro de 1856.)

A poesia de Sérgio Alcides tem seu ponto de partida no reconhecimento de uma espécie de fratura ambivalente da linguagem. Destituído de seu trono solar, o sujeito poético que assume a voz em Píer (2012), último livro do poeta, convive com um deslocamento, um hiato, uma diferença que marca sua alteridade em relação ao real, que guarda sempre uma certa distância de seus instrumentos de percepção. $O$ índice maior desse aparente divórcio está na descoberta da linguagem como linguagem, da poesia como poesia, graças à presença de um "defeito" no olhar que 
chama a atenção para o próprio olhar, que traz para o primeiro plano o próprio mecanismo da representação:

\author{
Querer olhar para a lente, \\ Verificar a ranhura \\ da lente, não a que arranha \\ do outro lado da vista \\ o mundo menos real \\ - mas real - da circunstância. \\ Sem poder deixar de ver \\ - através - a poesia. \\ ("Está caindo", p. 11)
}

Se a ranhura da lente traz a própria lente para o primeiro plano da fotografia, ela, porém, nos convida a ver "através", a reconhecer a incontornável ambivalência da representação, destinada a se equilibrar sempre entre mimesis e semiosis. Não há, portanto, precedência do real sobre a palavra; mas tampouco pode se falar em intransitividade poética, à maneira dos formalistas. Se poemas como "Mas" (p.15) e "Frescobol"i (p. 21) dialogam com um certo discurso da intransitividade, isso ocorre mais como um exercício de problematização que como um elogio mesmo da incomunicabilidade e da recusa do real. Esse discurso parece funcionar, no conjunto da obra de Alcides, como uma espécie de recuo que visa a reafirmar a existência da "lente", isto é, da linguagem e da poesia como objetos autônomos (o que não quer dizer isolados). Em "Frescobol", vemos o poeta se preocupar com a manutenção da energia poética, com a sustentação do jogo que depende diretamente de um "diálogo entre raquetes". Essa bela alegoria da poesia e de sua relação ambivalente com o universo exterior parece apontar muito mais para a dialética do (re)conhecimento na diferençaii do que para a alienação na intransitividade da forma. Assim como a linguagem poética, a bolinha azul do frescobol desempenha o papel de um tipo de mediação que não se reduz ao caráter instrumental que Walter Benjamin (2000, p. 156) enxerga na concepção burguesa da linguagem, reduzida a uma teoria antipoética da significação que associa arbitrariamente 
as palavras e as coisas, esvaziando, assim, tanto o potencial semiótico quanto o potencial mimético da palavra poética.

Nesse espaço do "através", no qual se realiza a poesia de Alcides, a linguagem poética se mostra parcial, partida e repartida entre um sujeito fraturado e o real mutável e inapreensível como totalidade. Sujeito às intempéries da história, esse real se inscreve não raro como catástrofe, como barbárie, como destruição, como crise do sentido, como veremos mais adiante. Como na cena aparentemente ingênua de um dia na praia, retratada no poema "Castelos" (p.23), nossas construções simbólicas são erigidas com a mesma "areia" que compõe a vastidão impessoal da praia, e por isso estão sujeitas a se dissolverem nela. Além da precariedade do sentido, essa imagem aponta também para a matéria prima natural - mineral, no caso - da própria significação. Possível herança de Augusto dos Anjosiii, para quem a consciência não passa de um estágio da matéria

4

a correspondência entre a palavra (poética em especial) e a natureza, em Sérgio Alcides, pode ser melhor explicada pela adesão crítica do poeta ao modo alegórico moderno. Para compreender a presença da alegoria na poesia de Alcides é necessário, antes de tudo, esclarecer, com Walter Benjamin (2011, p. 173), que "a alegoria (...) não é uma retórica ilustrativa através da imagem, mas expressão, como a linguagem, e também a escrita." Entendida dessa forma, como representação, a alegoria aparece como o mecanismo mesmo da "lente arranhada", isto é, como a linguagem ambivalente que se denuncia como parcial em sua própria transparência. Também ambivalente, a alegoria benjaminiana se caracteriza como uma "curiosa combinação de natureza e história" (Benjamin, 2011, p. 178). Ela está baseada na imbricação da matéria e do sentido, associando o mecanismo natural da degeneração e o mecanismo artificial da imposição a posteriori do conceito, da ideia, do significado. Essa imbricação nos leva a compreender a natureza e a história como escritura, isto é, como índices fragmentários de uma totalidade irrecuperável. Essa "antinomia do alegórico" (Benjamin, 2011, p. 186) está associada à própria duplicidade da história no 
pensamento do século XVII. Segundo Benjamin (2011, p. 186), “(...) do mesmo modo que a doutrina barroca entendia a história em geral como uma série de acontecimentos criados, assim também em particular a alegoria, sendo convenção como qualquer outra escrita, era vista como criada, tal como a sagrada". Leitura e escritura fragmentada de uma totalidade irrecuperável, a alegoria se define, assim, como uma experiência duplamente e circularmente melancólica: enquanto escritura, ela reproduz um deslocamento que está na base da concepção barroca (e moderna) da história e da própria natureza, marcada pela não coincidência entre o "ser imagético" e o "significado" (Seligmann-Silva, 1999, p. 91); esse processo, por sua vez, é inseparável de uma espécie de atentado contra a realidade atingida pelo olhar melancólico, que mata e conserva ao mesmo tempo o objeto da representação:

Se um objeto, sob o olhar da melancolia, se torna alegórico, se ela lhe sorve a vida e ele continua a existir como objeto morto, mas seguro para toda a eternidade, ele fica à mercê do alegorista e dos seus caprichos. $E$ isto quer dizer que, a partir de agora, ele será incapaz de irradiar a partir de si próprio qualquer significado ou sentido; o seu significado é aquele que o alegorista lhe atribui (Benjamin, 2011, p. 1996).

A imbricação entre a catástrofe histórica e a natureza está na base do modo alegórico que marca alguns poemas de Píer. No poema "Assentamentos", que abre a suíte intitulada "Margem do São Francisco", a mesma experiência de descolamento da imagem e do significado descrita acima se faz presente. O poema, contudo, reforça a ambivalência da alegoria, que não deixa de remeter a uma força primitiva, a uma realidade perdida porém inscrita fragmentariamente na natureza e na linguagem:

No sertão tudo se torna alegoria

A seriema não se distrai de ser um signo.

De dia, o anu-preto apita seus anúncios.

De noite, uma rasga-mortalha corta os hábitos noturnos.

O céu está em ordem, mas pesa nas costas do rio. 
(O santo flui por intermédio).

O céu assiste sem ironia às obstinações que passam.

Logo acima do grão de terra já fica o céu.

O céu se apresenta em demasia.

Onde é real, parece um sonho.

A paisagem toda forma uma leitura.

Quem chega, é como ter nascido e ser amparado por uma letra A.

(“Assentamentos", p. 111)

O poema representa uma natureza inteiramente convertida em signo. O diálogo direto com Baudelaire (1975, p. 86), para quem "tout devient allégorie" durante seu passeio pelos canteiros de obra da Paris do Segundo Império no famoso poema Le Cygne, é mais um elemento que reforça o caráter incontornável da abordagem linguística do mundo, a impossibilidade de uma visada ingênua, "distraída", primordial, pré-literária da realidade. Poema e natureza estão sujeitos à mesma lei de fragmentação do sentido, que está na base do modo alegórico. Essa lei, como vimos acima, guarda a ambivalência da destruição e da preservação vi. Se as profundas transformações pelas quais passa a cidade de Paris sob Napoleão III despertam em Baudelaire a memória de um outro tempo - mítico e histórico , o sertão brasileiro, por sua vez, figura natural convertida em figura histórica pela prática dos "assentamentos", não deixa de guardar também a memória de um tempo perdido, anterior à significação, anterior à história, o tempo da natureza "distraída", ao qual o poema se remete em negativo, conservando-o como "objeto morto." Se "a paisagem toda forma uma leitura" é porque a imbricação entre a natureza e a história é uma espécie de a priori da percepção, ao menos para a modernidade poética - pós-romântica - fundada por Baudelaire, para quem mito e história, natureza e linguagem são dimensões profundamente entrelaçadas. vii Marcadamente alegórica, a experiência poética baudelairiana se equilibra entre a memória do sagrado e a sujeição ao "tempo devorador e destruidor" da modernidade (Gagnebin, 2007, p. 49). No caso da poesia de Alcides, em especial aquela que se reúne em Píer, é interessante observar mais uma vez que a precedência absoluta da significação, reafirmada no verso final de "Assentamentos ("quem chega, 
é como ter nascido e ser amparado por uma letra A"), aponta menos para o elogio da intransitividade verbal que para a afirmação de uma espécie de turbidez crítica da linguagem, isto é, para a sua capacidade de representar a realidade desvelando, no ato mesmo da representação, a sua diferença em relação ao real, sua identidade verbal ou semiótica.

O poeta que afirma não haver corpos nem tempo "fora desta mancha gráfica" ("Mas", p. 15) é o mesmo que não recusa o caminho contrário ao da significação, quando a natureza é convocada "a se instalar nas palavras, / insinuar-se nas sílabas / (...) a fim de restituir / a folha de tinta / ao som, à voz" ("Coluna”, p. 13). Essa passagem do verbo gráfico ao som e à voz soa como uma espécie de restauração, ainda que provisória, de uma energia poética - rara, é verdade - mais próxima da natureza que do poeta, dando origem a uma palavra inspirada autônoma, independente de qualquer centro subjetivo:

Coisa não minha, vai e diz tua inspiração sozinha.

(“Coluna", p. 13)

Contudo, a oscilação entre a significação e a memória fragmentada de um sentido primordial inscrita na própria palavra não será o único movimento da poesia de Sérgio Alcides. Para além da crise baudelairiana do sentido, materializada na própria ambivalência do modo alegórico, encontramos no poeta carioca um movimento em direção ao exterior da alegoria. Isso ocorre como uma espécie de crítica/crise que se dá na própria trama da representação poética e termina por chamar a atenção para os limites da própria significação diante da catástrofe, do absurdo da história. É o que podemos verificar em um poema que, paradoxalmente e não por acaso, se constrói a partir da recuperação de uma alegoria: o Angelus Novus de Paul Klee retomado por Walter Benjamin (1994, p. 226) em suas teses Sobre o conceito de história. Intitulado "Nosso Angelus", o poema de Alcides apresenta uma espécie de transfiguração histórica da alegoria benjaminiana, ao representá-la no contexto da Ditadura Militar brasileira. Ao contrário do 
anjo de Klee e Benjamin, o "anjo da história do Brasil" não pode mais ver a história do alto, pois é representado não apenas como testemunha, mas principalmente como vitima da tirania dos personagens da própria história:

Olhar esbugalhado. Sujo de terra, sujo de ter visto demais

Uma tempestade sopra aí. Não vem do paraíso.

Talvez siga para lá.

Mas nem mesmo é uma tempestade.

Berro. Canivete. Cassetete. Coturno. Porão. Pua.

O trópico é o pau de arara onde foi pendurado o anjo da [história

do Brasil, para ser torturado.

Aura escangalhada, sem chance de alegoria.

Asas abertas porque foram quebradas, asas repuxadas.

Boca aberta porque foi atada ao cano de descarga de um jipe da Força Aérea em 1971, que acelerou e o arrastou pela boca até o fim e depois.

Sem que pudesse enxergar as ruínas atrás.

Desenho de manchas de sangue no pátio de cimento, projeto de rachaduras futuras sob o trópico.

Revelação / ocultamento / desvio e retorno em abismo.

Nenhum anjo deixou cadáver.

Para ser engolido. E nunca ser encontrado.

Sem que possamos encerrar a busca.

(Alcides, p. 75-76)

O poema narra uma espécie de queda da alegoria no tempo da catástrofe, onde o anjo é tomado como um prisioneiro da Ditadura e conhece 
o horror da tortura imposta pelos militares a milhares de presos políticos durante as décadas de 60 e 70. Geográfica e historicamente localizado nos "trópicos", o anjo da nossa história é a tal ponto brutalizado que sua dimensão divina - o sagrado fragmentário da alegoria - é aniquilado ("Aura escangalhada, sem chance de alegoria"). É a alegoria da morte da alegoria.

Tomada de assalto pela própria história - no absurdo do autoritarismo brasileiro, a alegoria é como um anjo de asas quebradas impedido de se distanciar para ver ("sem que pudesse enxergar as ruínas atrás"). Tragada pelo tempo profano da história, e não mais pela tempestade do paraíso, como em Benjamin, ela se vê ameaçada em sua capacidade de representar, atingida em cheio naquilo que melhor a define: sua condição ambivalente de ser ao mesmo tempo palavra, signo e memória da coisa. Degradado pela tortura, o anjo que não pode mais ver é como a alegoria que não pode mais significar, ou ainda, a linguagem humilhada pela barbárie.

Essa alegoria do aniquilamento da linguagem - que aponta, em última instância, para uma espécie de dramatização poética da vitória do absurdo sobre a inteligência - é construída a partir de uma sofisticada imbricação de elementos metafóricos, que remetem à própria experiência poética, e elementos metonímicos que remetem à história do Período Militar brasileiro. Vejamos como isso ocorre, por exemplo, na caraterização inicial da própria figura do anjo. Seu "olhar esbugalhado e sujo de terra" guarda a duplicidade da vidência, componente central da alegoria benjaminina, e da cegueira - ou da mudez - imposta às vítimas do regime militar. Metaforicamente, seu olhar esbugalhado é uma lembrança de seu poder mítico; metonimicamente, é a marca da opressão, uma referência à tortura como instituição. Na elaborada construção do poema, essa dicotomia se desdobra mais uma vez, se considerarmos que a tortura do anjo não se presta somente a uma leitura metonímica, mas se volta mais uma vez sobre a própria alegoria, convidando-nos a interpretá-la como um poderoso questionamento a respeito das dificuldades de se atribuir algum sentido claro à catástrofe. Em resumo, a figura do anjo aprisionado no terreno da história anuncia o movimento perpétuo de desdobramento em direção ao real e recolhimento sobre si 
mesma realizado pela linguagem. Enquanto alegoria da alegoria torturada, o "anjo da história do Brasil" se oferece como uma espécie de crítica da razão histórica, sem, contudo, jamais flertar com qualquer sombra de irracionalismo. Além dos olhos, a mesma operação poética é aplicada na descrição das outras partes do corpo do anjo: as asas abertas porque quebradas; a boca aberta porque atada a um jipe da Força Aérea. Nos dois casos, a alegoria benjaminina é conservada e destruída, ao mesmo tempo, graças ao contato corrosivo com barbárie histórica. No segundo exemplo, na descrição da boca do anjo, a cena da tortura é acrescida de pormenores prosaicos, como a descrição do veículo ao qual o anjo e atado e a referência ao ano de 1971, que atentam contra o halo poético original da figura do anjo ao mesmo tempo que aproximam consideravelmente o poema do registro histórico.

Ao reescrever a alegoria de Benjamin, Alcides realiza uma alegoria da falência da alegoria, uma dramatização poética da crise do sentido em tempos de catástrofe. Nesse aspecto, o que ocorre é uma espécie de ultratensionamento do modo de representação alegórico, posto "em abismo" pela alegoria do anjo torturado, procedimento que o próprio poema é capaz de tematizar metapoeticamente, ressaltando o duplo movimento descrito acima de desdobramento e recolhimento da linguagem, de abertura e fechamento para o real, de "Revelação / ocultamento / desvio e retorno // em abismo", fórmula que nos leva de novo à proposição inicial deste artigo a respeito da fratura ambivalente da linguagem, proposição que se exemplifica com perfeição pelo emprego crítico e autocrítico que a poesia de Alcides faz da alegoria. Confirmando sua vocação de enxergar o mundo "através" da "lente arranhada" da linguagem, que, nesse processo de representação da realidade, representa-se também a si mesma, o poeta carioca inscreve sua poesia num espaço essencialmente crítico.

\section{Referências}

ALCIDES, Sérgio. Píer. São Paulo: Editora 34, 2012. 
ALCIDES, Sérgio. "Augusto dos Anjos e o mito do Eu" In: ETTORE FinazziAgró, Roberto Vecchi e Maria Betânia Amoroso (orgs.). Travessias do póstrágico: os dilemas de uma leitura do Brasil. São Paulo: Unimarco Ed., 2006.

ANJOS, Augusto dos. Obra Completa. Rio de Janeiro: Nova Aguilar, 2004.

BENJAMIN, Walter. "Tese sobre o conceito de história". Magia e técnica, arte e política: ensaios sobre literatura e história da cultura. $7^{a}$ edição. Trad. Sérgio Paulo Rouanet. São Paulo: Brasiliense, 1994. - (Obras Escolhidas v. 1)

BENJAMIN, Walter. Passagens. Belo Horizonte: Editora UFMG; São Paulo: Imprensa Oficial Do Estado de São Paulo, 2006.

BENJAMIN, Walter. Origem do drama trágico alemão. Trad. João Barrento. Belo Horizonte: Autêntica, 2011.

DEGUY, Michel. La poésie n'est pas seule, court traité de poétique. Paris: Seuil, 1987.

GAGNEBIN, Jeanne Marie. História e narração em Walter Benjamin. $2^{\mathrm{a}}$ edição. São Paulo: Perspectiva, 2007.

LIMA, Luiz costa. Mímesis: desafio ao pensamento. Rio de Janeiro: Civilização Brasileira, 2000.

JACKSON, John E. "Mythe et histoire dans Les Fleurs du mal" In: L'Année Baudelaire 13/14. Paris: Honoré Champion, 2011.

SELIGMANN-SILVA, Márcio. Ler o livro do mundo: Walter Benjamin: Romantismo e crítica literária. São Paulo: Iluminuras, 1999.

\section{NOTAS}

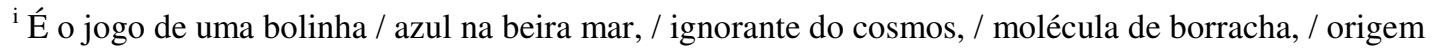
de toda vida, / imotadora da linha / do horizonte, embora móvel / diálogo entre raquetes, / bem expulso que regressa / mais possante, impulse bem, / mediadora entre solenes/ portadores de ray-ban, / no muscular passatempo / cujo único objetivo / é mantê-la sempre éria / e silêncio sobre o sol.

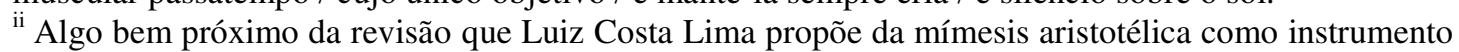
que estabelece uma relação de "mão dupla" com o real, definindo-se como um instrumento crítico de produção de diferença graças à criação de verossimilhança. Cf. Mímesis: desafio ao pensamento (2000, p. 25). Conjugando uma visão autônoma e uma visão representativa da arte, a poesia de Sérgio Alcides parece se realizar no "espaço do entre", sobre o qual fala Michel Deguy. Para o poeta e crítico francês, "Il s'agit "à la fin" de veiller sur la différence - appelons-la tantôt dedans-dehors - en démentant (...) les assimilations imprudentes, les identifications intolérantes et meurtrières, et les exclusions tranchantes jusqu'au sang." Michel Deguy, La poésie n'est pas seule, court traité de poétique, Paris, Seuil, 1987, p. 23. Veremos que este entre-lugar coincide em diversos aspectos com a alegoria teorizada por Walter Benjamin.
} 
iii Destacado intérprete da poesia de Augusto dos Anjos, Sérgio Alcides lê a poesia do autor de "Eu" à luz, justamente, da fragmentação do eu solar (expressão retirada de Luiz Costa Lima op. cit. p. 84) e, portanto, da derrota do sentido como instância metafísica e totalizante. Cf. o artigo de Alcides “Augusto dos Anjos e o mito do Eu" In: ETTORE Finazzi-Agró, Roberto Vecchi e Maria Betânia Amoroso (orgs.). Travessias do pós-trágico: os dilemas de uma leitura do Brasil. São Paulo: Unimarco Ed.,2006.

${ }^{4}$ Augusto dos Anjos entende que nossa faculdade produtora de sentido é fruto de um sofisticado processo neurológico. Cf. entre tantos outros, o poema "A Ideia": "De onde ela vem?! De que matéria bruta / Vem essa luz que sobre as nebulosas / Cai de incógintas criptas misteriosas / como as estalactites duma gruta?!" (Anjos, Augusto dos. Obra Completa. Rio de Janeiro: Nova Aguilar, p. 204).

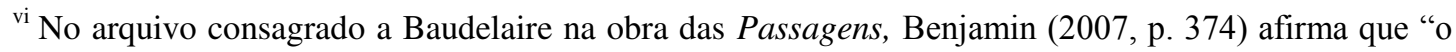
objeto atingido pela intenção alegórica é segregado das relações da vida: ele é ao mesmo tempo quebrado em pedaços e conservado."

vii A respeito da tensão entre o mito e a história em Baudelaire, remeto o leitor à excelente leitura do poema Le Cygne feita por John E. Jackson no ensaio intitulado "Mythe et histoire dans Les Fleurs du mal' In: L'Année Baudelaire 13/14. Paris: Honoré Champion, 2011.
} 